\title{
Clinico-Radiological Factors Affecting Outcome of Supratentorial Spontaneous Intracerebral Hemorrhage: A Single Institute Experience
}

\author{
Yogi $\mathbf{N}^{1}$, Thulung $\mathrm{S}^{2}$, Sharma $\mathbf{P}^{3}$ \\ ${ }^{1}$ Department of Neurosurgery, Manipal Teaching Hospital, Pokhara, Nepal \\ ${ }^{2}$ Department of Neurosurgery, Upendra Devkota Memorial National Institute of Neurological \\ and Allied Sciences, Kathmandu, Nepal \\ ${ }^{3}$ Department of Radiology and Imaging, Manipal Teaching Hospital, Pokhara, Nepal
}

Received: March 10, 2019

Accepted: April 25, 2019

Published: June 30, 2019

Cite this paper:

Yogi N, Thulung S, Sharma P. Clinico-Radiological Factors Affecting Outcome of Supratentorial Spontaneous Intracerebral Hemorrhage: A Single Institute Experience. Nepalese Journal of Radiology 2019;9(13):12-17. https://doi.org/10.3126/njr.v9i1.24809

\begin{abstract}
:
Introduction: Intracerebral bleeds are the second most common cause of stroke. The initial consciousness level and progressive deterioration and various radiological parameters like hematoma volume, its expansion, mass effect and location has been implicated with poor outcomes of Intracerebral Hematoma (ICH) regardless of the management methods. In this study we aimed to study various clinical and radiological parameters associated with outcome of spontaneous supratentorial ICH.
\end{abstract}

Methods: This prospective study was carried out in 89 patients of spontaneous supratentorial ICH admitted to National Institute of Neurological and Allied Sciences, Nepal in between January 2015 to December 2015 to assess various parameters associated with its outcome. Outcome of the patients were assessed against various clinic-radiological and demographic variables using chi square test and student's t test respectively for categorical and continuous variables using IBM SPSS 20 software.

Results: Glasgow Coma Scale (GCS) $(p=0.00)$, size of hematoma $(p=0.034)$, presence of midline shift $(0.000)$ and presence of intraventricular hematoma $(p=0.020)$ were found to have statistically significant difference when compared in between good and poor outcome group.

Conclusion: GCS at admission, size of hematoma, midline shift in cerebral tomography scan (CT scan) and presence of intraventricular hemorrhage (IVH) were significantly associated with outcome of spontaneous Supratentorial ICH.

Keywords: Humans; Glasgow Coma Scale; Prospective Studies; Chi-Square Distribution; Consciousness; Cerebral Hemorrhage

\section{INTRODUCTION:}

Correspondence to: Dr. Nikunja Yogi

MBBS, MS, Mch (Neurosurgery)

Departmentof Neurosurgery

Manipal Teaching Hospital

Pokhara, Nepal

Email: yoginikunj@hotmail.com
Intracerebral bleeds are the second most common cause of stroke, accounting for $30-60 \%$ of hospital admissions for stroke. ${ }^{1}$ 
In 1961, McKissock and colleagues reported the first prospective randomized controlled trial in neurosurgery and showed that operative treatment was associated with a worse outcome than conservative treatment for patients with spontaneous supratentorial intracerebral haemorrhage. ${ }^{2}$ That trial has affected the management of this disorder for most of the past half century. In 1989, Auer and co-workers reported the opposite result in a trial of endoscopic removal of hemorrhage in 100 patients. $^{3}$ In the same year, this finding was contradicted by Juvela and colleagues but the trial was too small to detect less than a substantial effect of surgery. ${ }^{4}$ Since these three initial trials, a further six have been reported and meta-analysis of the first seven has shown no firm conclusions regarding the role of operative treatment. ${ }^{5}$ Improved surgical techniques, neuroimaging, neuroanaesthesia, and perioperative monitoring and care have all led to improved outcomes from surgery in many conditions. ${ }^{6}$

The initial consciousness level and progressive deterioration and various radiological parameters like hematoma volume, its expansion, mass effect and location has been implicated with poor outcomes of ICH regardless of the management methods. ${ }^{7,8}$ Studies investigating factors affecting the outcome of spontaneous ICH are very scarce in our country.

In this study we aimed to study various clinical and radiological parameters associated with outcome of spontaneous supratentorial ICH.

\section{METHODS}

This prospective study was carried out in National Institute of Neurological and Allied Sciences, a tertiary care neurosurgical center in Nepal with an aim to assess various clinicradiological parameters associated with outcome of spontaneous supratentorial ICH. A total of 89 patients, aged 22-77 years, with a diagnosis of Spontaneous Supratentorial Intracerebral Hemorrhage (ICH) admitted in the hospital from January 2015 to December 2015 were included in the study after obtaining approval from the Institutional Review Board. All these patients had at least six months of follow up. data were collected on patient's demography, accompanying symptoms as well as physical and neurological finding, CT and Magnetic Resonance Imaging (MRI) findings and intervention required/done. Surgical indication in our study was any patients having basal ganglionic hematoma more than $50 \mathrm{ml}$, temporal lobe hematoma more than $20 \mathrm{ml}$, hematoma in other lobes more than $30 \mathrm{ml}$, midline shift of more than $10 \mathrm{~mm}$ and deterioration in patient treated conservatively secondary to increase in hematoma size or mass effect due to perilesional edema. Clinical deterioration was defined as fall in GCS by two points or drop in one point of motor score of GCS and increase or asymmetry in size of pupil. Outcome was assessed as Modified Rankin score (MRS) at six months with a pre-structured questionnaire form at follow up. For the ease of assessment MRS was dichotomized to Good Outcome (MRS 1, 2 and 3) and Poor Outcome (MRS 4, 5 and 6).

$\mathrm{ICH}$ due to aneurysms or arteriovenous malformations or those secondary to tumor or trauma were excluded from the study. Similarly cerebellar and brainstem bleed or extension of bleed to the brainstem were also excluded. Patients who had abnormal coagulation profile, those on anticoagulants and those who had severe pre-existing physical or mental disability or severe co-morbidity which might interfere with assessment of outcome were also excluded from the study.

Outcome of the patients were assessed against various clinico-radiological and demographic variables using chi square test and student's t test respectively for categorical and continuous variables using IBM SPSS 20 software. 


\section{RESULTS:}

There were 102 patients fulfilling the study criteria admitted to our hospital during the study period out of which six patients got discharged against advice during the course of treatment and seven patients were lost in follow up. Thus only 89 patients were included in the study. The various clinical parameters of the patients are tabulated in
Table 1 . The only clinical parameters showing significant difference between the good and poor outcome groups was GCS ( $p=0.00)$.

The various radiological parameters are listed in Table 2. Size of hematoma $(p=0.034)$, presence of midline shift (0.000) and presence of IVH $(p=0.020)$ were found to have statistically significant difference when compared in between good and poor outcome group.

Table 1: Various Clinico-demographic parameters

\begin{tabular}{|c|c|c|c|c|}
\hline S.N & Clinical Variables & Good Outcome & Poor Outcome & P value \\
\hline 1 & Age (52.27 SD 12.28) (27-77 Yrs) & $51.63(\mathrm{SD} 11.71)$ & $54.33(\mathrm{SD} 14.11)$ & 0.382 \\
\hline 2 & $\begin{array}{l}\text { Sex } \\
\text { Male }(71.9 \%) \\
\text { Female }(28.1 \%) \\
\end{array}$ & $\begin{array}{l}49(76.6 \%) \\
19(76 \%)\end{array}$ & $\begin{array}{l}15(23.4 \%) \\
6(24 \%) \\
\end{array}$ & 0.955 \\
\hline 3 & $\begin{array}{l}\text { GCS } \\
3-4(2.2 \%) \\
5-12(31.5 \%) \\
13-15(66.3 \%)\end{array}$ & $\begin{array}{l}0(0 \%) \\
15(53.6 \%) \\
53(89.8 \%)\end{array}$ & $\begin{array}{l}2(100 \%) \\
13(46.4 \%) \\
6(10.2 \%)\end{array}$ & $0.000 *$ \\
\hline 4 & $\begin{array}{l}\text { Hypertension } \\
\text { No }(33.7 \%) \\
\text { Yes }(66.3 \%)\end{array}$ & $\begin{array}{l}22(73.3 \%) \\
46(78 \%)\end{array}$ & $\begin{array}{l}8(26.7 \%) \\
13(22 \%)\end{array}$ & 0.627 \\
\hline 5 & $\begin{array}{l}\text { Diabetes Mellitus } \\
\text { No }(52.8 \%) \\
\text { Yes }(47.2 \%)\end{array}$ & $\begin{array}{l}37(78.7 \%) \\
31(73.8 \%)\end{array}$ & $\begin{array}{l}10(21.3 \%) \\
11(26.2 \%)\end{array}$ & 0.586 \\
\hline 6 & $\begin{array}{l}\text { Smoking } \\
\text { No }(44.9 \%) \\
\text { Yes }(55.1 \%)\end{array}$ & $\begin{array}{l}31(77.5 \%) \\
37(75.5 \%)\end{array}$ & $\begin{array}{l}9(22.5 \%) \\
12(24.5 \%)\end{array}$ & 0.826 \\
\hline 7 & $\begin{array}{l}\text { Alcohol } \\
\text { No } 49.4 \% \\
\text { Yes } 50.6 \%\end{array}$ & $\begin{array}{l}34(77.3 \%) \\
34(75.6 \%)\end{array}$ & $\begin{array}{l}10(22.7 \%) \\
11(24.4 \%)\end{array}$ & 0.849 \\
\hline 8 & $\begin{array}{l}\text { Intervention } \\
\text { Conservative } 77.5 \% \\
\text { Operation } 22.5 \%\end{array}$ & $\begin{array}{l}55(79.7 \%) \\
13(65 \%)\end{array}$ & $\begin{array}{l}14(20.3 \%) \\
7(35 \%)\end{array}$ & 0.172 \\
\hline
\end{tabular}

\section{DISCUSSION}

Spontaneous ICH has been described as the disease of elderly population with male preponderance. In our study the mean age of patients was 52.27 years with $71.9 \%$ of them being males, which is in accordance with the literature..$^{9,10,11}$
In our series, $42(66.3 \%)$ cases had Hypertension (HTN) which was comparable to other study where $50-70 \%$ patients had HTN. HTN is the most important risk factor for spontaneous intracerebral hemorrhages. In studies of patients with hypertensive ICH, persistently elevated blood pressure increased the risk for hematoma progression. ${ }^{10,12}$ 
Table 2: Various Radiological Parameters of ICH

\begin{tabular}{|c|c|c|c|c|}
\hline S. $\mathbf{N}$ & Radiological Parameter & Good Outcome & Poor Outcome & P value \\
\hline 1 & $\begin{array}{l}\text { Side } \\
\text { Left }(50.6 \%) \\
\text { Right }(49.4 \%) \\
\end{array}$ & $\begin{array}{l}35(77.8 \%) \\
33(75 \%)\end{array}$ & $\begin{array}{l}10(22.2 \%) \\
11(25 \%)\end{array}$ & 0.758 \\
\hline 2 & $\begin{array}{l}\text { Location } \\
\text { Lobar }(20.2 \%\} \\
\text { Putaminal }(61.8 \%) \\
\text { Thalamus }(18 \%)\end{array}$ & $\begin{array}{l}14(77.8 \%) \\
45(81.8 \%) \\
9(56.2 \%)\end{array}$ & $\begin{array}{l}4(22.2 \%) \\
10(18.2 \%) \\
7(43.8 \%)\end{array}$ & 0.130 \\
\hline 3 & $\begin{array}{l}\text { Midline Shift } \\
\text { No }(79.8 \%) \\
\text { Yes }(20.2 \%) \\
\end{array}$ & $\begin{array}{l}58(81.7 \%) \\
10(55.6 \%) \\
\end{array}$ & $\begin{array}{l}13(18.3 \%) \\
8(44.4 \%) \\
\end{array}$ & $0.020^{*}$ \\
\hline 4 & $\begin{array}{l}\text { Intraventricular Hematoma } \\
\text { No }(73 \%) \\
\text { Yes }(27 \%)\end{array}$ & $\begin{array}{l}58(89.2 \%) \\
10(41.7 \%)\end{array}$ & $\begin{array}{l}7(10.8 \%) \\
14(58.3 \%)\end{array}$ & $0.000^{*}$ \\
\hline 5 & $\begin{array}{l}\text { Size } \\
0-35 \mathrm{ml}(70.8 \%) \\
>35 \mathrm{ml}(29.2 \%)\end{array}$ & $\begin{array}{l}52(82.5 \%) \\
16(61.5 \%)\end{array}$ & $\begin{array}{l}11(17.5 \%) \\
10(38.5 \%)\end{array}$ & $0.034^{*}$ \\
\hline
\end{tabular}

In our study, the most common location of hemorrhage was putamen in 55 cases $(61.8 \%)$ followed by various lobes of the brain in 18 cases $(20.2 \%)$ and thalamus in 16 cases (18\%). In a study conducted by Anderson et al, the most common location of spontaneous ICH was putamen (43\%) followed by various cortical lobes $(23 \%)$ and thalamus $(20 \%){ }^{13}$

In our study there was a significant difference between good and poor outcome groups in terms of GCS. Poor GCS at admission corresponded significantly with higher MRS at 6 months. International surgical trial in ICH (STICH) showed comatose patients $(\mathrm{GCS}<8)$ with $\mathrm{ICH}$ in basal ganglia or thalamus were very unlikely to benefit from surgery. ${ }^{14}$ Similarly other studies also suggest that outcome of ICH is affected significantly by admission GCS in terms of functional outcome and mortality. $15,16,17,18,19$

Size of the hematoma was another factor showing statistical difference with outcome in our study. Many studies have found volume to be a strong predictor of functional outcome and death in humans, regardless of the treatment modality. ${ }^{15,16,17,18,19,20}$
Mckissock reported the first randomized study of surgical removal of ICH during the pre-CT era. Outcomes in terms of death or disability were poor in surgical arm than in conservative. However, McKissocks study was done at a time when technologies both operative and anesthesiological as well as post-operative intensive care differed substantially from those used today. ${ }^{2}$ Juvela and colleagues reported a randomized study of surgery versus best medical therapy for 52 patients with spontaneous supratentorial $\mathrm{ICH}$. There was no difference in functional outcome and mortality between surgically and conservatively treated patients. ${ }^{4}$ In our study there was no statistically significant difference in outcomes when compared against surgically and conservatively managed patients.

IVH was found to be significantly associated with outcome in our study. IVH leads to obstruction of CSF flow due to clots formation in ventricular system leading to subsequent obstructive hydrocephalus and generalized edema. Most of the relevant studies provide evidence that IVH as well as midline shift in CT scan suggesting mass effect and features of herniation is significantly associated with increased mortality and poor outcomes. ${ }^{15,16,17,18,19}$ 


\section{CONCLUSION}

GCS at admission, size of hematoma, midline shift in CT scan and presence of intraventricular hemorrhage were significantly associated with outcome of spontaneous supratentorial ICH.

\section{CONFLICT OF INTEREST}

None

\section{SOURCES OF FUNDING}

None

\section{REFERENCES:}

1. Dennis M. Outcome after brain hemorrhage. Cerebrovas Dis 2003;16:9-13. https://doi.org/10.1159/000069935

2. McKissock W, Richardson A, Taylor J. Primary intracerebral hemorrhage: a controlled trial of surgical and conservative treatment in 180 unselected cases. Lancet 1961;278(7196):221-226. https://doi.org/10.1016/S01406736(61)90353-1

3. Auer LM, Deinsberger W, Niederkorn K. Endoscopic surgery versus medical treatment for spontaneous intracerebral hematoma: a randomized study. $J \quad$ Neurosurg 1989;70(4):530-535. https://doi.org/10.3171/ jns.1989.70.4.0530

4. Juvela S, Heiskanen O, Poranen A. The treatment of spontaneous intracerebral hemorrhage: a prospective randomized trial of surgical and conservative treatment. J Neurosurg 1989;70(5):755-758. https://doi.org/10.3171/ jns.1989.70.5.0755

5. Teernstra O, Evers S, Lodder J. Stereotactic treatment of intracerebral hematoma by means of plasminogen activator: a multicenter randomized controlled trial (SICHPA). Stroke 2003;34(4):968-974. https://doi.org/10.1161/01. STR.0000063367.52044.40

6. Nehls DG, Mendelow AD, Graham DI. Experimental intracerebral hemorrhage: early removal of a spontaneous mass lesion improves late outcome. Neurosurgery 1990;27(5):675-682. https://doi.org/10.1227/00006123199011000-00002

7. Siddique MS, Fernandes HM, Wooldridge TD. Reversible ischemia around intracerebral hemorrhage: a single-photon emission computerized tomography study. J Neurosurg 2002;96(4):736-741. https://doi.org/10.3171/ jns.2002.96.4.0736

8. Shaw MDM, Mendelow AD, Teasdale GM, Murray GD, Gregson BA. Alterations to STICH protocol. Lancet 2003;362(9391):1244. https://doi.org/10.1016/S0140$\underline{\text { 6736(03)14530-8 }}$

9. Brott T, Broderick J, Kothari R et al. Early hemorrhage growth in patients with intracerebral hemorrhage. Stroke 1997;28(1):1-5. https://doi.org/10.1161/01.STR.28.1.1

10. Okazaki H, Whisnant J. Clinical pathology of hypertensive intracerebral hemorrhage. New York, NY: Raven Press Publishers; 1983:177-180.

11. Fisher CM. Pathological observations in hypertensive cerebral hemorrhage. $J \mathrm{Neu}$ ropathol Exp Neuro 1971;30(3):536-550. https://doi.org/10.1097/00005072197107000-00015

12. Counsell C, Boonyakarnkul S, Dennis M et al. Primary intracerebral hemorrhage in the Oxfordshire community stroke project. Cerebrovasc Dis 1995;5(1):26-34. https://doi.org/10.1159/000107814

13. Anderson CS, Chakera TM, StewartWynne EG et al. Spectrum of primary 
intracerebral haemorrhage in Perth, Western Australia. J Neurol Neurosurg Psychiatry 1994;57(8):936-940. https://doi.org/10.1136/jnnp.57.8.936

14. Broderick JP, Brott T, Tomsick T. The risk of subarachnoid and intracerebral hemorrhages in blacks as compared with whites. $N$ Engl J Med 1992;326(11):733-736. https://doi.org/10.1056/ NEJM199203123261103

15. Broderick JP, Brott TG, Duldner JE, Tomsick T, Huster G. Volume of intracerebral hemorrhage. A powerful and easy-to-use predictor of 30-day mortality. Stroke 1993;24(7):987-993. https://doi.org/10.1161/01.STR.24.7.987

16. Nag C, Das K, Ghosh M, Khandakar MR. Prediction of clinical outcome in acute hemorrhagic stroke from a single CT scan on admission. $N$ Am J Med Sci 2012;4(10):463-467. https://doi.org/10.4103/1947$\underline{2714.101986}$
17. Hemphill JC 3rd, Farrant M, Neill TA $\mathrm{Jr}$ Prospective validation of the $\mathrm{ICH}$ Score for 12-month functional outcome. Neurology 2009;73(14):1088-1094. https://doi.org/10.1212/ WNL.0b013e3181b8b332

18. Hallevy C, Ifergane G, Kordysh E, Herishanu Y. Spontaneous Supratentorial intracerebral hemorrhage. Criteria for short-term functional outcome prediction. J Neurol 2002;249(12):1704-1709. https://doi.org/10.1007/s00415-002$\underline{\text { 0911-1 }}$

19. Zia E, Engstrom G, Svensson PJ, Norrving B, Pessah-Rasmussen H. Three-year survival and stroke recurrence rates in patients with primary intracerebral hemorrhage. Stroke 2009;40(11):3567-3573. https://doi .org/10.1161/ STROKEAHA.109.556324

20. Masdeu JC, Rubino FA. Management of lobar intracerebral hemorrhage: medical or surgical. Neurology 1984;34(3):381-383. https://doi.org/10.1212/WNL.34.3.381 